\title{
Impact Analysis of Interference Sources on Data Communication System for CBTC application
}

\author{
Wang Shaoyin ${ }^{1, a}$, Yu yi ${ }^{1, b}$, Zheng Guoxin ${ }^{2, c}$ and Ding Qingfeng ${ }^{2,3, d}$ \\ ${ }^{1}$ Shanghai Maglev Transportation Engineering R\&D Center, Shanghai, China; \\ ${ }^{2}$ Key Laboratory of Specialty Fiber Optics and Optical Access Networks, Shanghai University, \\ Shanghai 200072, China; \\ ${ }^{3}$ School of Electrical and Electronic Engineering, East China Jiaotong University, NanChang \\ 330013, China \\ adhw1021@163.com, byuyi@smtdc.com, gxzheng@staff.shu.edu.cn, dbrandy724@sina.com
}

Keywords: DCS; C/I ; Interference

\begin{abstract}
We study the anti-interference performance of the 802.11 system when it works as Data Communication System (DCS) in Communication Based Train Control (CBTC). We first conduct extensive experiments on a $802.11 \mathrm{~b}$ network to assess the ability on a lab test bed, then the outdoor experiments are also conducted. In the presence of jammer, we find that in each case of interference model, there exists a C/I threshold which determine the DCS-Access Point (DCS-AP) and DCS-Station Adapter (DCS-STA) communication performance. In the outdoor environment, different interference sources are adopted to investigate the data throughput value and other parameters of the DCS system under the critical state.
\end{abstract}

\section{Introduction}

Nowadays, most of the CBTC systems in China use WLAN technology as its Data Communication System which setting wireless link between train and railway side [1-2]. DCS contains DCS-Access Points (DCS-AP) which on the railway side and DCS-Station Adapters (DCS-STA) which on the locomotives. Because WLAN is working in the $2.4 \mathrm{GHz}$ ISM band which is unlicensed, the variety of devices operates in this band and the rising RF interference disturbs CBTC somehow.[3-4] The technologies applied in DCS for CBTC application to counteract interference contain modulation, directive antennas, channel access scheme as well as carrier sense and collision avoidance. The two carrier frequencies are often used to realize frequency diversity to enhance the DCS system performance. Some papers evaluate the effectiveness of such devices in vehicle environments [5]. In this paper we consider $802.11 \mathrm{~b}$ as a DCS system which using DSSS. When DCS and interference source are using the same spreading method at the same band, for example both systems are WiFi, the DCS performance is dramatically degraded. In this case carrier to Interference ratio (C/I) will be critical. On the other hand, if DCS and Interference source are using different modulation schemes. For example, the DCS is $802.11 \mathrm{~b}$ using DSSS and the interference source is Bluetooth using FHSS, the impact will be less. The designers often make radio coverage to calculate carrier over interference [6]. They should consider following factors: the transmit output power, connector and cable losses, splitter and combiner losses, transmit antenna gain, path loss, receive antenna gain and receiver sensitivity. To evaluate the interference effect accurately, we conduct extensive experiments on a $802.11 \mathrm{~b}$ network to assess the system ability on a lab test bed, and also in the outdoor environment to simulate practical electromagnetic case. And we focus on the DCS and interference systems are both using DSSS technology. The paper is organized as followings: Part 1 we illuminate the experiments in lad test bed. Part 2 the DCS-STA performance under interference on the ground is presented. Part 3 shows DCS-AP performance under interference on the ground. Part 4 is the conclusion. 


\section{Test arrangement in lab}

To test the anti-interference performance of DCS, the architecture was set up as in Fig 1 in which the AP and STA are tested, the Agilent E4437B vector generator and WiFi-AP are set as interference sources. The vector generator is used to transmit AWGN with $10 \mathrm{M}$ bandwidth and adjustable power. The test system contains Agilent 11667A splitter and Agilent 8496B adjustable attenuator. DEMO software is applied to present measurement data.

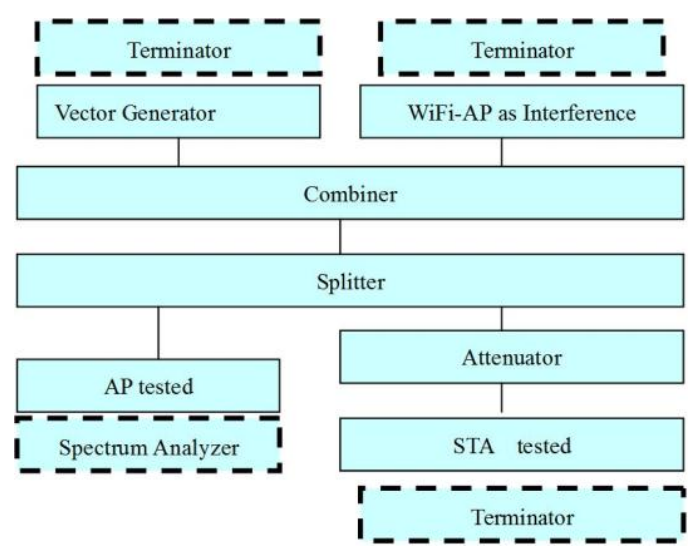

Fig. 1 Carrier to interference ratio testing scheme

In cases of testing received power, some devices should be replaced by terminators or spectrum analyzer shown as dashed blocks in Fig. 1. First the DCS under the interference of AWGN is tested, while WiFi-AP is switched off and the AWGN is transmitted from the generator. The DCS carrier central frequency is $2458 \mathrm{MHz}$. When AWGN power is $-40 \mathrm{dBm}$, the spectrum analyzer indicates $-65 \mathrm{dBm} / 10 \mathrm{MHz}$ or $-75 \mathrm{dBm} / 1 \mathrm{MHz}$ for interference. The DCS power is $-72.36 \mathrm{dBm} / 1 \mathrm{MHz}$. The test results are presented as in table 1 .

Table. 1 DCS single carrier under interference

\begin{tabular}{|c|c|c|c|c|c|c|}
\hline \multicolumn{2}{|c|}{ Carrier power } & \multicolumn{2}{|c|}{ Interference power } & \multirow{2}{*}{$\frac{\mathrm{C} / \mathrm{I}(\mathrm{dB})}{\mathrm{C}_{2} / \mathrm{I}_{2}}$} & \multirow{2}{*}{$\begin{array}{l}\text { Throughout } \\
\text { loss }(\%) \\
\text { F2 }\end{array}$} & \multirow{2}{*}{$\begin{array}{l}\text { performance } \\
\text { F2 }\end{array}$} \\
\hline $\begin{array}{l}\text { Read by } \\
\text { software } \\
(\mathrm{dBm})\end{array}$ & $\begin{array}{l}\text { Read by } \\
\text { analyzer } \\
(\mathrm{dBm} / \mathrm{MHz})\end{array}$ & $\begin{array}{l}\text { Set in } \\
\text { generator } \\
(\mathrm{dBm})\end{array}$ & $\begin{array}{l}\text { Read at test } \\
\text { point } \\
(\mathrm{dBm} / \mathrm{MHz})\end{array}$ & & & \\
\hline-73 & \multirow{2}{*}{-72.36} & \multirow{2}{*}{-40} & \multirow{2}{*}{-75} & \multirow{2}{*}{2.64} & 94.35 & failure \\
\hline-71 & & & & & 91.79 & failure \\
\hline-73 & \multirow{2}{*}{-72.36} & \multirow{2}{*}{-42} & \multirow{2}{*}{-77} & \multirow{2}{*}{4.64} & 56.2 & failure \\
\hline-73 & & & & & 59.51 & failure \\
\hline-73 & \multirow{2}{*}{-72.36} & \multirow{2}{*}{-45} & \multirow{2}{*}{-80} & \multirow{2}{*}{7.64} & 4.72 & pass \\
\hline-73 & & & & & 7.53 & pass \\
\hline
\end{tabular}

The results shows according to the DCS requirements, the below two rows are satisfied, while the top four rows are failure. Secondly, DCS works at two carriers which transmitting the same data for frequency diversity. The central frequencies are $2408 \mathrm{MHz}$ and $2458 \mathrm{MHz}$. The interference source WiFi-AP is switched on and the transmitting frequency is $2412 \mathrm{MHz}$ which interferes with the carrier 1 . WiFi-AP is set as test mode and interference $\mathrm{I} 1$ is $10 \mathrm{~dB}$ higher than carrier $\mathrm{C} 2$. At the test point, the spectrum analyzer shows that $\mathrm{I} 1$ is $-29.7 \mathrm{dBm} / 22 \mathrm{MHz}$ or $-43.1 \mathrm{dBm} / 1 \mathrm{MHz}$. The DCS power for $\mathrm{C} 1$ and $\mathrm{C} 2$ is $-72.3 \mathrm{dBm} / 1 \mathrm{MHz}$. Thus

$\mathrm{C} 1 / \mathrm{I} 1=(-72.3)-(-43.1)=-29.2 \mathrm{~dB}$

The test results are shown in table 2 . 
Table.2 DCS double carrier under interferences

\begin{tabular}{|c|c|c|c|c|c|c|c|c|c|c|c|c|}
\hline \multicolumn{2}{|c|}{$\begin{array}{l}\text { Carrier } \\
(\mathrm{dBm} / \mathrm{MHz})\end{array}$} & \multicolumn{2}{|c|}{$\begin{array}{l}\text { Interference } \\
(\mathrm{dBm} / \mathrm{MHz})\end{array}$} & \multicolumn{2}{|c|}{$\mathrm{C} / \mathrm{I}(\mathrm{dB})$} & \multicolumn{2}{|c|}{$\begin{array}{l}\text { Throughout } \\
\text { loss }(\%)\end{array}$} & \multirow{2}{*}{$\begin{array}{l}\begin{array}{l}\text { Response } \\
\text { time(s) }\end{array} \\
\mathrm{F} 2\end{array}$} & \multirow{2}{*}{$\begin{array}{l}\text { FER } \\
(\%) \\
\text { F2 }\end{array}$} & \multicolumn{2}{|c|}{ Performance } & \multirow{2}{*}{$\begin{array}{l}\text { DCS } \\
\text { performa } \\
\text { nce }\end{array}$} \\
\hline $\begin{array}{l}\text { F1: } \\
\text { C1 }\end{array}$ & $\begin{array}{l}\mathrm{F} 2: \\
\mathrm{C} 2\end{array}$ & WiFi:I1 & Generator:I2 & $\mathrm{C} 1 / \mathrm{I} 1$ & $\mathrm{C} 2 / \mathrm{I} 2$ & $\mathrm{~F} 1$ & $\mathrm{~F} 2$ & & & $\mathrm{~F} 1$ & $\mathrm{~F} 2$ & \\
\hline \multirow[b]{2}{*}{-72.3} & \multirow[b]{2}{*}{-72.4} & \multirow[b]{2}{*}{-43.1} & \multirow[b]{2}{*}{-75} & \multirow[b]{2}{*}{-29.2} & \multirow[b]{2}{*}{2.64} & 100 & 92.19 & 21.71 & 83.87 & failure & failure & failure \\
\hline & & & & & & 99.7 & 86.89 & 31.03 & 75.3 & failure & failure & failure \\
\hline \multirow{2}{*}{-72.3} & \multirow{2}{*}{-72.4} & \multirow{2}{*}{-43.1} & \multirow{2}{*}{-77} & \multirow{2}{*}{-29.2} & \multirow{2}{*}{4.64} & 99.61 & 46.06 & 1.89 & 19.25 & failure & failure & failure \\
\hline & & & & & & 100 & 43.6 & 1.42 & 20.16 & failure & failure & failure \\
\hline \multirow{2}{*}{-72.3} & \multirow{2}{*}{-72.4} & \multirow{2}{*}{-43.1} & \multirow{2}{*}{-80} & \multirow{2}{*}{-29.2} & \multirow{2}{*}{7.64} & 100 & 1.18 & 0 & 0 & failure & pass & pass \\
\hline & & & & & & 100 & 2.21 & 0 & 0 & failure & pass & pass \\
\hline
\end{tabular}

When DCS two carriers both under the AWGN interference, and $\mathrm{C} / \mathrm{I} \leq 4.64 \mathrm{~dB}$, the throughout loss is higher than $10 \%$ and carrier is considered as failure. When $\mathrm{C} / \mathrm{I} \leq 2.64 \mathrm{~dB}$, the throughout loss is very high and the response time is $26.37 \mathrm{~s}$ which greater than standard $3 \mathrm{~s}$, the FER is $79.85 \%$ which greater than standard $30 \%$. Then the DCS system is considered as failure. At the bottom row, because carrier 2 is not interfered and transmit the same information, then the DCS system fit the requirement. The test data read from DEMO software and that from spectrum analyzer is very close and the difference is less than $1 \mathrm{~dB}$.

\section{DCS-STA under interference on the ground}

The more tests are conducted in cases of DCS-STA under the interferences of some systems working in the ISM band, such as WiFi, PTP (P-com AUFSD-2G1). The tests are carried out on the ground as shown in Fig. 2. The AP is at the right side position $\mathrm{D}(0 \mathrm{~m}, 0 \mathrm{~m})$ of the street and the $\mathrm{SA}$ is placed at the left side, positions of A1(340m, 0m), A2(320m, 0m), A3(300m, 0m), A4(280m, 0m), A5(260m, 0m), while the interference is placed at position of $\mathrm{I} 1(283 \mathrm{~m}, 11 \mathrm{~m})$.

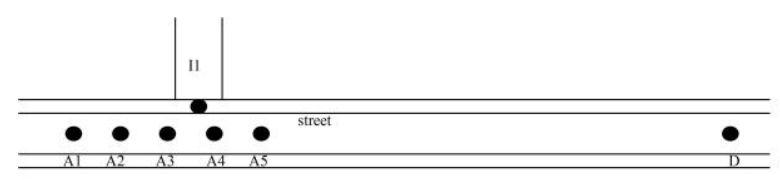

Fig.2 Test arrangement on the ground

The tested system works in frequency diversity state which two working frequency channels are used to transmit the same data apart. There are two interference models: The first one is that only one working frequency is under the interference while the other working frequency works without any interference. The second model is that two working frequency work under interferences. The carrier power is adjusted by changing the attenuations. Figure 3 shows DCS-STA performance under the interferences of WiFi. Figure 4 shows DCS-STA performance under the interferences of PTP. 


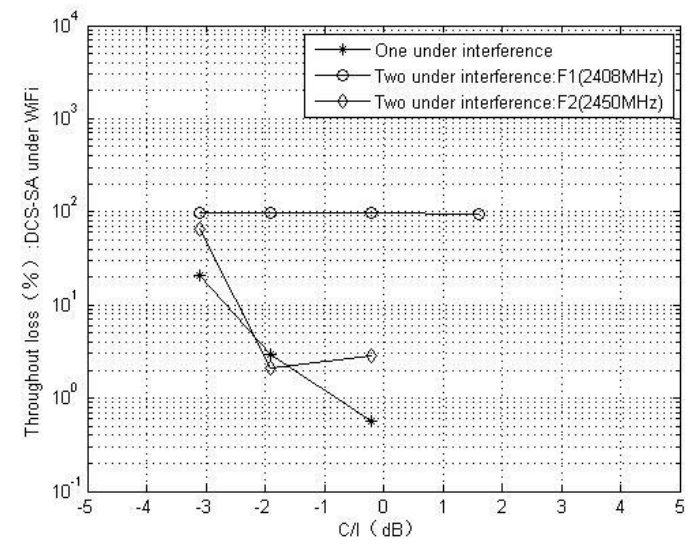

Fig.3 DCS-STA under the interferences of WiFi.

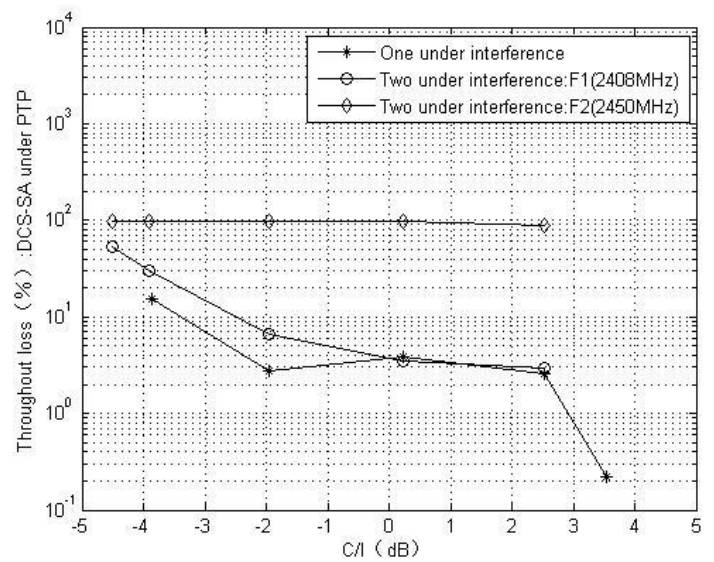

Fig.4 DCS-STA under the interferences of PTP

\section{DCS-AP under interference on the ground}

The more tests are carried out in cases of DCS-AP under the interferences of some systems working in the ISM band, such as Wi-Fi, PTP. Figure 5 shows DCS-AP performance under the interferences of Wi-Fi. Figure 6 shows DCS-AP performance under the interferences of PTP.

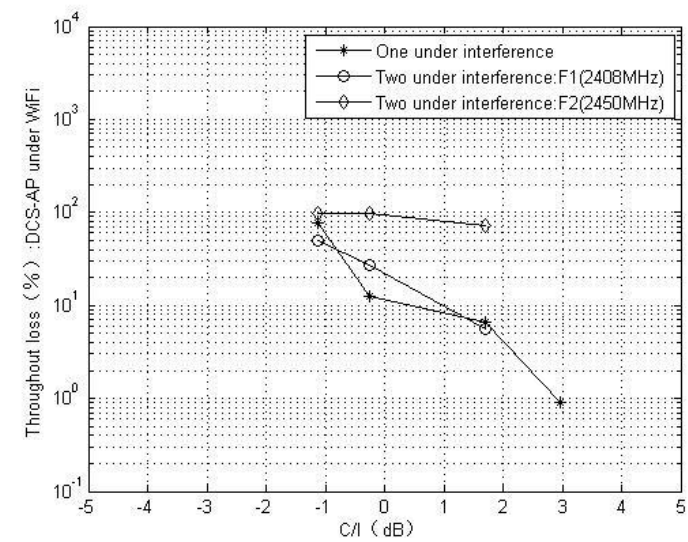

Fig.5 DCS-AP under the interferences of WiFi. 


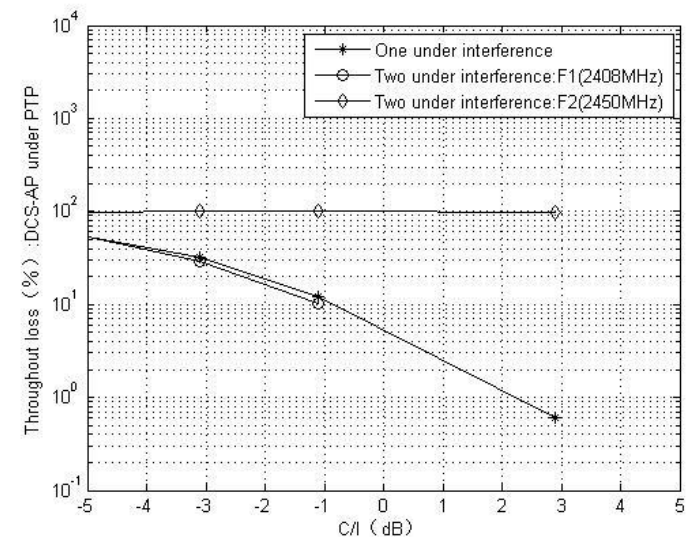

Fig.6 DCS-AP under the interferences of PTP

\section{Conclusion}

In case of DCS uses DSSS technology and the interference sources are also use the same modulation, the $\mathrm{C} / \mathrm{I}$ and the throughput is investigated. As far as single frequency is considered, when $\mathrm{C} / \mathrm{I}$ is less than or equal to $4.64 \mathrm{~dB}$, the channel does not reach the standard for the throughput loss. Outdoor tests show that the DCS throughput loss is worse due to interference of WiFi than that duo to PTP. The results will help designers to avoid DCS system degradation duo to potential interferences.

\section{Aknowledgement}

This work is supported by Shanghai Leading Academic Discipline Project S30108, NSFC 61132003 and NSFC 61171086.

\section{References}

[1] Xu, Tianhua, Tang, Tao; Gao, Chunhai; Cai, Dependability analysis of the data communication system in train control system, Science in China, Series E: Technological Sciences, v 52, n 9, p 2605-2618, September 2009.

[2] Fitzmaurice, M., Use of $2.4 \mathrm{GHz}$ frequency band for Communications Based Train Control data communications systems, Rail Conference, 2006. Proceedings of the 2006 IEEE/ASME Joint , pp.263-267, 4-6 April 2006

[3] Huang Chuanhe; Cheng Yong; Li Yuan; Shi Wenming; Zhou Hao; An Interference-aware and Power Efficient Topology Control Algorithm for Wireless Multi-hop Networks, Pervasive Computing and Communications, Sixth Annual IEEE International Conference, pp.330-335, 17-21 March 2008.

[4] Bu Bing; Wang Hongwei; Zhao Hongli; Jiang Hailin, A research on the hybrid train-to-ground communication method in CBTC, Service Operations, Logistics, and Informatics (SOLI), 2011 IEEE International Conference, pp.512-516, 10-12 July 2011.

[5] Heddebaut, M. In-vehicle WLAN radio-frequency communication characterization, Intelligent Transportation Systems, IEEE Transactions on, Volume: 5: 114 - 121, June 2004.

[6] Kolyadenko, Yu.Yu. Analysis of electromagnetic compatibility of wireless local area networks, Telecommunications and Radio Engineering, v 66, n 8, p 741-751, 2007. 